\title{
Formation of Cognitive Flexibility as a Basic Competence of the Future Teachers' Multicultural Personality
}

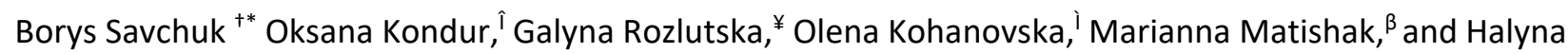
Bilavych ?

\section{Abstract}

The article presents the results of research work on the formation of cognitive flexibility (CF) as an essential competence of the future teachers' multicultural personality. It has been shown that various branches of knowledge (psychology, philosophy, clinical medicine, pedagogy and others) contribute to the scientific and theoretical substantiation of CF, which is included in the TOP-10 most requested competencies in the XXI century. Based on the analysis of the essence and nature of the future teachers' multicultural personality, the hypothesis that the competence of CF should become a vital component of personal development was put forward. To test this hypothesis, a pedagogical experiment was organised, which covered 33 future teachers studying "Educational, Pedagogical Sciences" at the Precarpathian National University (Ivano-Frankivsk, Ukraine). The experiment was conducted in four stages: on the first preparatory stage, a defined program of experimental activities was made; on the second statement stage, the diagnosis of future teachers' CF levels was set on the basis of the developed prognostic tools (the Questionnaire Cognitive flexibility was created to define the main features of CF as a component of multicultural competence of the future teacher, tests); on the third formative stage the approbation of our methodology for the formation of CF was carried out, which had no analogues in modern education and pedagogy (this was implemented on the basis of our own special course "Cognitive flexibility and multicultural competence of the future teacher", which was held as a training seminar); on the fourth control stage the results of the experiment were determined. They showed that the indicators of CF formation of future teachers at a high level increased from $9.1 \%$ to $41.5 \%$ (4.7 times), at the medium level they decreased from $63.6 \%$ to $53 \%$ (1.2 times). At the low level, they changed from $27 \%$ to 5.5\% (4.9 times) according to four defined criteria (cognitive abilities, adaptive abilities, the flexibility of thinking, and emotional flexibility). This proves the effectiveness of the authors' methodology for the formation of CF as a basic competence of the multicultural personality of the future teacher. It can be widely used in the training of specialists in various specialities.

Keywords: Cognitive Flexibility; Multicultural Competence; Future Teacher; Flexibility of Thinking; Emotional Flexibility.

\footnotetext{
${ }^{\dagger}$ Doctor of History, Professor, Professor of Department of Pedagogy named after Bogdan Stuparik Vasyl Stefanyk Precarpathian National University, Corresponding Author, Ivano-Frankivsk, Ukraine

${ }^{*}$ Corresponding Author, Email: boris_savchuk@ukr.net

I Doctor of Pedagogy, Dean of Pedagogical Faculty of Vasyl Stefanyk Precarpathian National University, Associate Professor of the Department of professional techniques and technologies of primary education, Ivano-Frankivsk, Ukraine, Email: oxikon13@gmail.com

¥Doctor of Pedagogical Sciences, Associate Professor, Professor of Department of General Pedagogy and Pedagogy of Higher School, State University, Uzhhorod National University, Uzhhorod, Ukraine, Email: Grozlutska@ukr.net

' Doctor of Pedagogical Sciences, Associate Professor of the Department of Theory and Methodology of Educational Disciplines Teaching, Communal Higher Educational Establishment, Kherson Academy of Continuing Education of Kherson Regional Council, Ukraine, Email: aninamama.ks@gmail.com

${ }^{\beta}$ Candidate of pedagogical sciences, Associate Professor, Vasyl Stefanyk Precarpathian National university, Ivano-Frankivsk, Ukraine, Email: marianna.mathishak@pnu.edu.ua

'Doctor of Pedagogy, Professor, Department of Pedagogy of Primary Education, Vasyl Stefanyk Precarpathian National University, Ivano-Frankivsk, Ukraine, Email: ifosuhcvas@gmail.com

(C) 2020 Savchuk et al. This is an Open Access article distributed under the terms of the Creative Commons Attribution License (http://creativecommons.org/licenses/by/2.0), which permits unrestricted use, distribution, and reproduction in any medium, provided the original work is properly cited.
} 


\section{Introduction}

The development of multicultural education is an urgent need of the globalised world and an essential factor in the sustainable development of countries in the XXI century. Its growing importance is due to migration processes, globalisation of the labour market, ethnodemographic changes, the spread of electronic communications and more (Marginson \& Sawir, 2012; Moshnjaga, 2017). Multiculturalism is becoming a universal philosophy of the modern world. Under such conditions, there is a growing need to form a multicultural personality of the teacher, who has a great responsibility for the education of ethnic consciousness and tolerance of young people and adults. To be successful in this field, an individual must have competencies that meet the challenges of the rapidly changing world.

In 2016, the World Economic Forum in Davos presented the results of a study which aimed to determine the 35 most requested basic skills among the competencies of the XXI century. The results were based on a survey of about 13 million people who worked in 2,500 campaigns in 9 leading industries, including education, in 13 countries: China, India, the United States, Brazil, Japan, Mexico, Germany, France and others. Here are the TOP-10 competencies: complex problem solving, critical thinking, creativity, people management, coordinating with others, judgment and decision-making, service orientation, negotiation, cognitive flexibility (Global Challenge Insight Report, 2016). The Davos Forum in 2020 stated that the formation of these skills should become a compass for the development of educational policy and learning in all countries of the world (World Economic Forum, 2020).

The abovementioned issues allow us to hypothesise that cognitive flexibility (CF) should become one of the essential competencies of forming a multicultural personality of the future teacher. To test it, the research work was organised, which had no analogue in the theory and practice of modern pedagogy and education. In this study, the research consisted of two parts: a theoretical and methodological part and a pedagogical experiment, which are covered in the following sections. The study then ends with concluding remarks.

\section{Theoretical and Methodological Substantiation of Research Work}

The theoretical and methodological analysis of the essence of CF and ethnocultural personality of the future teacher involves determining their common semantic characteristics to justify the feasibility of a pedagogical experiment.

Cognitive flexibility is a complex, multilevel social phenomenon. This phenomenon is studied at the interdisciplinary level in terms of psychology, philosophy, clinical medicine, management, pedagogy and other fields of knowledge.

As a theoretical construct, CF originated in the field of psychology, which made a significant contribution to its development. From the standpoint of this science, it is interpreted as the mental ability to switch from one thought to another and reflect on several things at once; as the ability to adapt thinking or attention in response to changing circumstances, goals, and/or external stimuli (Martin \& Rubin, 1995; Scott, 1962). The first psychological experimental studies were aimed at finding out how the flexibility of cognitive abilities provides the solution of multiple "cognitively complex" problems (Scott, 1962: 407-409).

Cognitive neurobiology considers $\mathrm{CF}$ as a manifestation of human brain activity. From the standpoint of this science, CF is a crucial human ability allowing efficient adaptation to the challenges of changing task. Based on FMRI (functional magnetic resonance imaging), the researchers identified parts of the brain that respond to and regulate cognitive flexibility. Extrapolating this data to the realm of social life, they argue that "juggling multiple tasks simultaneously" is commonplace and amplified by the Internet, a wireless network (Leber et al., 2008).

Age physiology shows that the formation of CF begins in childhood. Moreover, it is regularly 
practised under different circumstances and ends at about 20 years of age. From the standpoint of this science, CF is seen as the ability to switch attention from one subject to another, to make choices, and to make alternative decisions. These abilities can be improved in the process of performing special exercises and tasks (Miyake et al., 2000: 54-76).

Based on the achievements of various fields of knowledge, scientists conceptualise CF as one of the highest abilities of metacognition and part of the executive functions of the high-level cognitive system that controls the flow of human thought. Components of $\mathrm{CF}$, such as working memory, planning, inhibition, and emotional balance, play an important role in human development, success in education, professional activities, and life. Based on executive functions, it formulates goals, organises, adjusts and controls activities, adapts to new circumstances, and achieves results (Executive Function Fact Sheet, 2005; Miyake et al., 2000).

The opposite of cognitive flexibility is cognitive rigidity (CR). It is seen as a violation and insufficiency of $\mathrm{CF}$, as an inability to change behaviour and beliefs; as a feeling/state when a person is stuck in one point/situation and cannot (is not able to /does not want to) find a way out of it (Scott, 1962; Kholodnaya, 2004).

The emergence of $C R$ is associated with the nature of the human brain, which tries to reduce uncertainty and therefore seeks stability. It is manifested in individuals as their desire to avoid change and novelty and to maintain the usual way of thinking and old patterns of behaviour. However, this method of adaptation to the environment is ineffective. A typical manifestation of $C R$ is perseveration, which is expressed in the repetition of actions; a duplication of operations that were effective before or in similar situations, but do not work under current conditions, inhibiting the achievement of new goals (Scott, 1962; Shapiro, 1981; Kholodnaya, 2004).

At the beginning of the XXI century, the Cognitive Flexibility Theory (CFTh) was formed, which is considered as a multilevel system that encompasses a body of knowledge about the phenomenon of CF. Education, as its essential component, has been actively studied since the 1990s, and we will find out about its essential aspects from the perspective of our study.

CFTh adherents criticise the "traditional" model of education as "linear" because the information is presented in a logical, consistent and structured form. The design of such training is reflected in school textbooks. However, as the amount of material increases, both its complexity and unstructuredness increase. Therefore, traditional linear learning loses its effectiveness because it cannot reflect different alternative views, does not allow to choose information, and does not develop creative thinking (Boger-Mehall, 1996).

At the beginning of the XXI century, CFTh's educational paradigm has evolved in line with the new challenges of a globalised society. Its cornerstones of "openness" and "flexibility" are defined as the basis for organising the learning process. It is claimed that learning according to the system of "ready knowledge presented in closed structures" limits the process of cognition, leads to "reductive prejudices", simplifies the understanding of the world and does not allow one to comprehend its diversity, and projects uniformity of thinking and rigidity of action (Spiro et al., 1991: 26-29; Spiro, Collins \& Ramchandran, 2007: 20-23).

These research results are of methodological importance for our research and experimental work. They focus on the selection of prognostic tools for determining the levels of mastery of CF and create a basis for the development of methods for CF formation as an essential competence of the multicultural personality of the future teacher.

Over the last half-century, the social and scientific discourse on the development of multicultural education has been growing. This problem has become globally discussed, so it seems paradoxical the total incapability of national university education systems for its salvation. There are some shortcomings and gaps in this area identified by scientists from different countries (Marginson \& Sawir, 2012; Moshnjaga, 2017): 
- strategies and teaching methods are not focused on preparing students for a harmonious, productive life in multicultural environments;

- curricula do not have semantic components that provide for the purposeful formation of multicultural competence as an important component of professional activity;

- there are no scientific concepts and strategies for creating international educational environments that would allow international students to adapt to new living conditions and ensure productive communication with local students and teachers very fast;

- students and teachers of local universities have a low level of multicultural competence. This is manifested in the preservation/dominance of ethnocentric attitudes, assessing the behaviour, views, and interests of international students through the prism of their national mentality;

- professional teachers have insufficient/no personal and professional experience of communication in a multicultural environment, etc.

Multicultural competence of the future teacher is defined as a set of qualities based on worldviews and knowledge, skills, abilities, and social experience, which allow adapting to life and working in new ethnocultural environments quickly, maintain emotional, behavioural stability, act flexibly, and make optimal decisions in different ethnic situations.

Multicultural and CF competences become a priority in the implementation of the leading trend and paradigm of educational development at the beginning of the XXI century - Lifelong Learning. The pedagogical discourse of Ukraine shares the functional understanding of the Indian sociologist P. Shukla of the essence of continuing education: "Education can no longer be considered as preparation for life. Education is life itself" (Astakhova, 2006: 67).
These principles are basic in the development of modern world systems. They agree with the principles of multicultural education, which include recognition of the values of cultural pluralism (as opposed to ethnocentrism), unity in diversity, choice of format and teaching methods that meet the principles of cultural diversity, problem-based learning, case studies and more.

Theoretical and methodological substantiation of research work allows us to go to its second experimental part.

\section{Pedagogical Experiment on the Formation of CF as a Competence of the Multicultural Personality of the Future Teacher}

The experiment involved solving two main tasks: the development of diagnostic tools and determining the level of formation of CF as a competence of the multicultural personality of the future teacher; the approbation of the author's methodology for its formation. In this case, the presented experiment in individual components or in general can be repeated and improved to solve identical and other problems of education and upbringing of different categories of the population creatively.

The experiment was conducted in four stages: 1) preparatory stage (development of diagnostic tools and author's methods); 2) ascertaining stage (diagnostics); 3) formative stage (introduction of the author's technique); 4) control stage (re-diagnosis to determine its effectiveness).

The research work was conducted between September-December 2019 at the Precarpathian National University (Ivano-Frankivsk, Ukraine). The experimental group (EG) of 33 people consisted of undergraduates majoring in "Educational, Pedagogical Sciences".

The developed diagnostic tool has no analogue in pedagogy and at the same time integrates known methods of determining the level of formation of various psychophysiological and professional characteristics of the individual, which are available through the Internet. They were creatively modified and adapted to the 
content and objectives of our research and experimental work.

Based on the essence and content of CFTh and multicultural competence, the four main criteria for the formation of CF as the competence of the multicultural personality of the future teacher and their main indicators are identified as:

- cognitive abilities (CA), that is, the possession of memory, psychophysiological and receptive skills and abilities for adequate perception and understanding of each culture as a unique system of values, attitudes, traditions, norms of behaviour, and beliefs that determine the importance of collective identity and its carrier; the interest in learning about the ethnocultural picture of the world and understanding its essence; the ability to use the means and strategies of verbal and nonverbal behaviour in accordance with the context and situation of intercultural dialogue and cultural expectations of its participants ethically and effectively; the possession of cognitive knowledge, skills, and abilities that encode and decode hidden cultural meanings to achieve intercultural understanding and interaction;

- adaptive abilities (AA), that is, the rapid adaptation to the living conditions of different ethnic communities; adequate psycho-cultural adaptability, which implies the abandonment of clear boundaries between one's "I" and the diversity of other personal and cultural contexts in a situation in relations with others; the ability to change behaviour, the nature of relationships, and activities according to changes in the socio-cultural situation easily; the ability to endure mistakes and changes in plans quickly and painlessly, to consider yourself in another person's shoes, to reach an understanding and common agreements, and to avoid conflicts;

- flexibility of thinking (FTh), that is, the conscious perception of multicultural diversity, an adequate response to changes in the ethnocultural environment; the awareness that all cultures are equally important as variants of human experience; the understanding of different dimensions of ethnocultural realities and different ("I-We" - "TheyOthers") views and assessments of the ethnocultural situation; the understanding of causal changes in the multicultural environment and interethnic relations; the possession of general systemic frameworks of thinking and ways of processing and analysis of information, which allows one to communicate in certain situations of intercultural interaction adequately and solve related tasks and problems effectively;

- emotional flexibility (EF), that is, the value of emotional perception of the realities of a multicultural society; the calm, tolerant response to specific behaviours of other cultures; the empathy for victims of interethnic conflicts and difficult social living conditions of different communities (poverty, disease, hunger, poor living conditions, inaccessibility to education, etc.); the adequate behaviour in situations of interethnic misunderstanding; maintaining a balance and tolerance in interethnic disputes and conflicts of a personal nature.

We present the prognostic tools used for determining the levels of $\mathrm{CF}$ formation at the ascertaining and control stages of the experiment and their functional characteristics.

The primary prognostic tool was the questionnaire "Cognitive Flexibility - a component of the future teachers' multicultural competence". It consisted of 120 questions, which were divided into four scales (30 questions each), which met the criteria of $C A$, $A A, F T h$, and EF. The purpose of the questionnaire was to find out the ideas, attitudes, reactions, actions and behaviours of future teachers in a multicultural environment 
that met these criteria. In its development, we had used methods of measuring the adaptability of A. Maklakov and S. Chermyanin; a method of measuring rigidity; methods of diagnosis of socio-psychological adaptation of K. Rogers and R. Diamond; methods for determining the psychological balance and risk of inadaptability of the St. Petersburg Military Medical Academy; methods of diagnosis of self-assessment of the mental state of G. Aizenko (Dashkov, \& Kurganskij, 1995).

The second group of prognostic tools concerned the determination of the levels of formation of individual CF criteria.

The Hidden Figures test was developed to measure short-range and short-term CA and FTh criteria based on well-known Gottschald figures. In our adapted version, in addition to measuring the flexibility of perception and independent vision, it performed cognitive functions. To do this, before testing, EG members were introduced to the images of 15 national symbols of different countries, such as the Eiffel Tower (France), a Lotus flower (India), the Trident (Ukraine) and others. On computer-generated cards, they were disguised among various geometric shapes. The task was to find and record them in four minutes. The number of correct answers determined the results: high level - from 15 to 11 points, medium - from 10 to 6, low - from 5 to 0 .

To determine the criterion of $A A$, the method of diagnosis of personality to prevent and respond to failure of T. Ehlers (Practical, 2006) was adapted and used. It essentially required the respondents to choose one of the three concepts (they were presented in 30 rows in the table), which most typically characterised their adaptive abilities. For example, "tolerant - open - receptive"; "bold - vigilant - enterprising"; "prudent - frivolous - timid"; "melancholic - has doubts - unstable"; "optimistic - vigilant carefree", etc. The results were calculated according to the key compiled by $\mathrm{T}$. Ehlers (1/2; $2 / 1 ; 3 / 1$, etc.) for 1 point for a certain answer. The higher the sum of points, the higher the level of flexibility and ability to prevent and avoid failures: high level - from 30 to 21 points; medium - from 20 to 11 points, low - from 10 to 1 points.

The method of free associations was adapted to determine the FTh criterion. Initially, EG members were asked to read a description of a Chinese pagoda that was chosen as a stimulus word. Then for four minutes, they wrote down the words associated with it. Their answers are classified into seven categories depending on the "size of the distance" of each named word relative to the word-stimulus: I - a direct description of the Chinese pagoda; II - the sacred purpose of the building; III - the interior; IV - the surrounding landscape; V - remote answers related to the concept of "pagoda"; VI - word game; VII - everything that did not relate to the pagoda (Kholodnaya, 2004).

The level of flexibility/rigidity of thinking of EG members was determined by the indicators "length of distance of free language associations" and "total number of answers in the protocol". The further away from the wordstimulus the words presented in free associations are, and the greater their number, the more pronounced the flexibility of thinking is. This technique also has a cognitive and educational value, because the members of the EG got acquainted in detail and consolidated their knowledge of the unique sacred structure.

The results of the observational experiment, which are further specified through comparison with the data of the control experiment, showed that most of the EG members had an average level of CF formation. This indicated the need for special training to improve this competence.

At the formative stage of the experiment, the author's method, which had no analogues in psychological and pedagogical science, was tested. Its features emphasise three aspects. The first is that the organic combination of two components - cognitive flexibility and multiculturalism -crystallised the fundamental task of forming CF as a basic competence for the development of the multicultural personality of the future teacher. The second aspect is the direct involvement in the development of this methodology of EG members, who thus 
increased their methodological training as an important component of professional culture.

The third aspect is manifested in the development of methods based on the synthesis of three types of sources: a) training technologies for the formation and development of cognitive and adaptive abilities, flexibility of thinking, emotional flexibility of the individual, and one's self-development and selfimprovement; b) psychological techniques for the formation of flexibility of mind, psyche, communication, behaviour, and others ) sociological, psychological, and pedagogical studies on the formation of multicultural competence of the individual (Adler, 1977; Moshnjaga, 2017; Slastenin \& Palatkina, 2004).

The main form of curriculum implementation of the experiment was arranged for EG members a special course called "Cognitive flexibility and multicultural competence of the future teacher", which was held as a training seminar. During ten days there were three trials of 1 hour and 20 minutes each.

The main method of conducting classes was individual and group training projects prepared by EG members and their joint discussion. They provided for the development of knowledge, skills, abilities, and personal qualities that meet specific criteria for the formation of CF as a competence of the multicultural personality of the future teacher. Each project was based on a specific source of information: "Facilitator's Code: Ethical Standards of Conduct in a Multicultural Environment" (according to the method of Flemming, 1996); "Maintain flexibility - change behavior in different environments" (according to Markmen, 2014); "Psychological flexibility - a safeguard of negative thoughts and feelings (according to the method of Dufren \& Sandoz, 2013); "Pedagogical flexibility and understanding of the student" (based on the ideas of Il'in, 2009); "Criticism tests of the flexibility of thinking" (according to the book by Kalugin, 2006 ); "Flexibility, adaptability, principle in dealing with the child" (according to Gippenreiter, 2013).

The project "Emotions of multicultural communication" (according to the book of Vem,
2010) was of great interest. Students learned to recognise the feelings and emotions of each person and representative of a different culture by their characteristic postures, gestures, facial expressions, speed and rhythm of movement, breathing rate and speech, pitch and intonation, etc. Then they took the appropriate tests.

Two mini-trainings took place within the framework of the special course. The first was on the topic "Model of intercultural communication" (according to the method of Flemming (1996)), which involved the modelling of various communicative situations in polyethnic, pedagogical, and student groups. Students acquired knowledge about differences in mental attitudes, behaviours of different cultures, and the ability to establish intercultural dialogue using verbal and nonverbal means of communication. During the second minitraining, "Teacher Balance: Models of Western and Eastern Cultures" (according to Flemming, 1996), EG members first studied their differences (for example, Europeans are constantly in a hurry, so they cannot wait, whereas oriental practices like Tai Chi, etc. teach first to achieve balance and concentration), and then moved on. Later they performed balance exercises (for example "Meditation", "Eye to Eye", etc.), which formed the skills of concentration, balance, and other states necessary for the formation of CF.

A number of educational tasks and exercises were developed and tested: "Situation and reaction" (how a teacher should act and react in standard and conflict situations in polyethnic environments of the university, secondary school etc.); "Raindrops" (the ability to avoid irritating topics and actions that degrade personal or national dignity; the ability to predict the consequences of certain statements and actions in ethnocultural environments); "The difference between desirable and undesirable" (the clarification of the principles and attitudes of creating a "safe space" in multicultural educational environments that provides impartial relations between its members, where there is discussion of only those problems that can be solved; evaluation of another culture as a 
reality, one's understanding as a person, and recognition of one's cultural values); "Emotion management: feedback" (working in microgroups to decipher emotional reactions and adjusting to help the interlocutor; involves empathy and the search for compromises, avoidance of accusations, exaggerations, distorted interpretations, etc.); "Colour and mood" (definition of colour according to changes in emotions and mental states; explanation of this interdependence), etc.

At the end of the special course, a control experiment was conducted on the basis of the same prognostic tools. Its results were compared with the data of the observational experiment and are presented in Table 1.

\begin{tabular}{|c|c|c|c|c|c|c|c|c|}
\hline \multirow[t]{2}{*}{$\begin{array}{l}\text { Criterion } \\
\text { Levels }\end{array}$} & \multicolumn{2}{|c|}{ Cognitive Abilities } & \multicolumn{2}{|c|}{ Adaptive Abilities } & \multicolumn{2}{|c|}{$\begin{array}{l}\text { Flexibility of } \\
\text { Thinking }\end{array}$} & \multicolumn{2}{|c|}{$\begin{array}{l}\text { Emotional } \\
\text { Flexibility }\end{array}$} \\
\hline & Before & After & Before & After & Before & After & Before & After \\
\hline High & $15.1 \%$ & $51.5 \%$ & $6.2 \%$ & $39.4 \%$ & $12.1 \%$ & $48.5 \%$ & $3.1 \%$ & $27.3 \%$ \\
\hline Medium & $63.6 \%$ & $48.5 \%$ & $57.4 \%$ & $54.4 \%$ & $69.7 \%$ & $42.4 \%$ & $63.6 \%$ & $66.5 \%$ \\
\hline Low & $21.3 \%$ & 0.0 & $36.4 \%$ & $6.2 \%$ & $18.3 \%$ & $9.1 \%$ & $33.3 \%$ & $6.2 \%$ \\
\hline
\end{tabular}

Source: Created by the Authors

Comparison of the general state of CF formation in EG members according to its four criteria on the output and input sections revealed that its average indicators at a high level increased from $9.1 \%$ to $41.5 \%$ (4.7 times), on average decreased from $63.6 \%$ to $53 \%$ (1.2 times), and at low decreased from $27 \%$ to $5.5 \%$ ( 4.9 times). This testifies to the effectiveness of the authors' method of forming CF as a basic competence of the multicultural personality of the future teacher. We believe that under conditions of creative use, it can be widely used in the training of specialists in various specialities.

\section{Conclusion}

The key aim of this research was to examine the formation of cognitive flexibility (CF) as a basic competence of the future teachers' multicultural personality. Thus, in the process of this research, it was found that $\mathrm{CF}$ is an essential competence for the formation of the future teacher as a holistic multicultural personality. The CF phenomenon has received a comprehensive justification in various fields of knowledge, which has become a theoretical and methodological basis for the organisation of our research work. The revealed agreement between the theoretical foundations of CF and multicultural competence was an important basis for this. To conduct a pedagogical experiment, the appropriate prognostic tools were adapted, and an original teaching method was developed and tested, which had no analogue in modern education and psychological and pedagogical science. Its effectiveness was evidenced by a comparison of the results of the ascertaining and control stages of the experiment. We believe that the represented experience of experimental work can find wide practical use in the formation of cognitive flexibility as an essential competence of training specialists in various fields of knowledge and specialities.

\section{References}

Adler, P. (1977). Beyond Cultural Identity:

Reflections on Multiculturalism. (R. Brislin, Ed.). Culture Learning, East-West Center Press, EastWest Centre Press.

https://www.mediate.com.adler3.

Astakhova, V.I. (2006). Continuing Education in the Context of Educational Reforms in Ukraine: monograph. Kharkov: Publishing House of the NAA.

Boger-Mehall, S.R. (1996). Cognitive Flexibility Theory: Implications for Teaching and Teacher Education. In B. Robin, J. Price, J. Willis \& D. 
Willis (Eds.). Society for Information Technology \& Teacher Education International Conference (9th, Washington, DC, March 10-14, 1998). https://www.learntechlib.org sprimary...

Dashkov, I., \& Kurganskij, N. (1995). Group testing of intelligence: the development of a universal technique. Theoretical and applied questions of psychology, 1 (2), (pp. 56-64). https://psyjournals.ru/psyedu/2005/n3/Baturin .shtml

Dufren, T., \& Sandoz, E. (2013). Living with Your Body and Other Things You Hate. New Harbinger Publications. https://www.bookdepository.com/Living-withYour-Body-Other-Things-You-Hate-Emily-KSandoz/9781608821044?pdg=dsa19959388920:cmp

Executive Function Fact Sheet. (2005). Learning Disabilities Executive Function Fact Sheet. Learning Disabilities: (NCLD). www.nsadhd.org > uploads.

Flemming, F. (1996). Transformational Dialogues. Facilitator Training Manual №1. An instruction manual of practical techniques for facilitating personal change.

http://www.worldtrans.org/TP/TP1/TP1TOP.HT $\mathrm{ML}$

Gippenreiter, Ju. B. (2013). The most important book for parents. Moskov: AST. http://sad54ptz.ru/inc/sad54/uf/editor/.../samaja_vaznaja_ kniga.pdf

Il'in, E. (2009). Psychology of creativity, artistry, giftedness. St-Petereburg: Piter.

http://parksgt.tsu.ru/upload/iblock/aa9/aa9d04 efbc67703011c9623eb383db15.pdf

Kalugin, R. (2006). Laws of the famous people https://eragozina.nethouse.ru/static/doc/0000/ 0000/0018/18848.Iw1ycut0q1.pdf

Kholodnaya, M. (2004). Cognitive styles. About the nature of the individual mind. St-

Petereburg: Piter.

http://www.ipras.ru/cntnt/rus/media/on-laynbibliote/knigi1/holodnaya_2.html

Leber, A. B., Turk-Browne, N. B., \& Chun, M. M. (2008). Neural predictors of moment-tomoment fluctuations in cognitive flexibility.
Proceedings of the National Academy of Sciences of the United States of America, 105, 36. 10.1073/pnas.0805423105.

Marginson, S., \& Sawir, E. (2012). Ideas for Intercultural Education. Palgrave Macmillan US. 237 p. https://doi. 10.1057/9780230339736.

Markmen, A. (2014). Rational changes. Minsk: Poppuri.

http://padabum.com/d.php?id=206517

Martin, M. M., \& Rubin, R. B. (1995). A new measure of cognitive flexibility. Psychological Reports, 76(2), 623-626. https://doi.org/10.2466/pr0.1995.76.2.623

Miyake, A., Friedman, N. P., Emerson, M. J., Witzki, A. H., Howerter, A., \& Wager T.D. (2000). The Unity and Diversity of Executive Functions and Their Contributions to Complex "Frontal Lobe" Tasks: A Latent Variable Analysis. Cognitive Psychology, 41(1), 49100. https://doi.org/10.1006/cogp.1999.0734

Moshnjaga, E. (2017). On the formation of a multicultural educational space in a university. Herald RTMAT, 1, 70-75.

https://cyberleninka.ru/article/n/k-voprosu-oformirovanii-multikulturnogo-obrazovatelnogoprostranstva-v-vuze

Practical psychodiagnostics. Methods and Tests. (2006). Samara: ID BAHRAH-M.

Scott, W.A. (1962). Cognitive Complexity and Cognitive Flexibility. Sociometry, 25(4), 405-414. https://doi.org/10.2307/2785779

Shapiro, D. (1981). Autonomy and rigid character. New York: Basic Books. https://doi.org/10.1037/h0085135

Slastenin, V., \& Palatkina, G. (2004).

Ethnopedagogical factors of multicultural education. Moskov

https://www.dissercat.com/content/etnopedag ogicheskie-faktory-multikulturnogoobrazovaniya

Spiro, R. J., Collins, B. P., \& Ramchandran, A. R. (2007). Modes of openness and flexibility in cognitive flexibility hypertext learning environments. In B. Khan, (Ed.), Flexible learning in an information society, (pp. 18-25). 
Hershey, PA: Information Science

Publishing.10.4018/978-1-59904-325-8.ch002

Spiro, R.J., Feltovich, P.J., Jacobson, M. \& Coulson, R.L. (1991). Cognitive flexibility, constructivism and hypertext: advanced knowledge acquisition in the structured domains. Educational Technology, 31(5), 2433.

https://www.researchgate.net/publication/200 772846_Cognitive_Flexibility_Constructivism_a nd_Hypertext_Random_Access_Instruction_for _Advanced_Knowledge_Acquisition_in_IIIStructured_Domains

Global Challenge Insight (2016). Report. The Future of Jobs Employment, Skills and Workforce Strategy for the Fourth Industrial Revolution. https://www.eduget.com.

Vem, A. (2010). Don't let you be cheated! Sign language: what Paul Ekman kept silent about. St-Petereburg: Piter. https://www.labirint.ru/books/237740/

World Economic Forum (2020). https://www.sncmedia.ru.

\section{Conflict of Interest}

The authors declare that there is no conflict of interest.

\section{Acknowledgements}

We would like to express our gratitude to the anonymous reviewers whose insights have helped in improving the paper. We also owe thanks to the journal for accepting the paper.

\section{Author Contribution Statement}

Borys Savchuk (corresponding author): conceptualisation; collecting references; developing the first draft with the incorporation of new ideas and relevant resources; data curation; methodology; re-writing the final draft; final reviewing of the draft and final editing.

Oksana Kondur, Marianna Matishak, and Halyna Bilavych: conducting empirical research and visualisation of data; analysed the data; collecting resources; initial reviewing and crosschecking for references; editing.

Galyna Rozlutska and Olena Kohanovska: methodology; contribution in software and validation of data, improve the quality of the article; editing.

All the authors read and approved the final manuscript. On behalf of the authors, the corresponding author declares that the author contributions mentioned above are correct, and all authors agree to the statements. 